\title{
Schistosome vaccines: a critical appraisal
}

\author{
R Alan Wilson ${ }^{+}$, Patricia S Coulson \\ Department of Biology, University of York, PO Box 373, YO10 5DD York, UK
}

An effective schistosome vaccine is a desirable control tool but progress towards that goal has been slow. Protective immunity has been difficult to demonstrate in humans, particularly children, so no routes to a vaccine have emerged from that source. The concept of concomitant immunity appeared to offer a paradigm for a vaccine operating against incoming larvae in the skin but did not yield the expected dividends. The mining of crude parasite extracts, the use of monoclonal antibodies and protein selection based on immunogenicity produced a panel of vaccine candidates, mostly of cytoplasmic origin. However, none of these performed well in independent rodent trials, but glutathione-S-transferease from Schistosoma haematobium is currently undergoing clinical trials as an anti-fecundity vaccine. The sequencing of the $\mathrm{S}$. mansoni transcriptome and genome and the development of proteomic and microarray technologies has dramatically improved the possibilities for identifying novel vaccine candidates, particularly proteins secreted from or exposed at the surface of schistosomula and adult worms. These discoveries are leading to a new round of protein expression and protection experiments that will enable us to evaluate systematically all the major targets available for immune intervention. Only then will we know if schistosomes have an Achilles' heel.

Key words: antigen - immune response - formulation - protection

For a variety of reasons, schistosomiasis remains an important parasitic disease of humans, its treatment and hence control being reliant on a single compound, praziquantel. An effective vaccine would be a useful adjunct and if sufficiently potent, a replacement for chemotherapy but the development of such a product has proved elusive. This review, primarily on Schistosoma mansoni, was compiled at the invitation of the organising committee and delivered at the Xth International Symposium on Schistosomiasis.

\section{Why develop a schistosome vaccine?}

It is pertinent at the outset to ask why we should want a schistosome vaccine - would it offer any advantages over chemotherapy? A strong argument has to be that schistosome infections are cryptic; they frequently go undetected and significant pathology has developed before chemotherapy is administered. Indeed, recent studies suggest that both morbidity and mortality have been seriously underestimated (van der Werf et al. 2003, King et al. 2005), especially what is sometimes referred to as subtle morbidity. It should also be borne in mind that single-dose chemotherapy is not completely effective in all patients. Praziquantel is inactive against the developing parasites and its efficacy at sub-curative levels may rely on host immune responses (Doenhoff et al. 1987). Furthermore, chemotherapy cannot prevent re-infection.

Financial support: The Wellcome Trust, Biotechnology and Biological Sciences Research Council, National Institutes of Health, the UNICEF/UNDP/World Bank/WHO Special Programme for Training in Tropical Diseases

${ }^{+}$Corresponding author: raw3@york.ac.uk

Received 25 May 2006

Accepted 26 June 2006
Low cure rates have been reported that may presage the appearance of drug resistance (Doenhoff et al. 2002). Lastly, schistosome infections are potent immunomodulators, a process that appears related to worm burden (Silveira et al. 2004), and may alter host responses to other infections in a deleterious manner.

It is also pertinent to ask what we want from a schistosomiasis vaccine. Unlike viral, microbial, and protozoan pathogens, schistosomes do not multiply in the mammalian host. The eggs they deposit in host tissues are the principal cause of pathology, which develops roughly in proportion to parasite burden. This means that sterile immunity induced by a schistosome vaccine is not essential. A significant reduction in worm burden would be a useful attribute as would a vaccine-induced reduction in the fecundity of female worms or the viability eggs.

\section{The first obstacle}

It is axiomatic that if a pathogen, however virulent, induces protective immunity as a result of an active infection, then the development of a vaccine against it is a feasible proposition. Schistosomes do not measure up well against this yardstick. The adult worms are adapted to life in the human bloodstream, a very hostile environment, where they can survive for $>30$ years (Harris et al. 1984) so must possess very effective immune evasion strategies. The standard experimental design to investigate human immunity, which relies on curative chemotherapy to permit reinfection rates to be determined, reveals little evidence for protection before puberty. Lower reinfection rates have been observed in adults, but it is by no means clear that they are solely the product of acquired immunity. Moreover, whilst there have been many studies of human immune responses, no obvious immune mechanisms have emerged on which to base a vaccine. This is especially true of mechanisms invoking $\mathrm{IgE}$ in effector responses. Given current knowledge of immunoglobulin heavy chain class switching, it is diffi- 
cult to envisage how antigens could be administered to elicit schistosome-specific IgE without also triggering bystander responses to irrelevant (environmental) antigens, with consequent risk of allergy. It is apparent that developing a schistosome vaccine for use in humans was never going to be easy.

\section{An early disappointment}

The first attempts to develop a schistosome vaccine began half a century ago. By analogy with successful microbial and viral vaccines, they involved the vaccination of mice with crude worm extracts or purified components, followed by a cercarial challenge (e.g. Sadun \& Lin 1959, Murrell et al. 1975, Hayunga 1985). The results were equivocal with 20,30 , and even $50 \%$ reduction in worm burden recorded, but there was a lack of consistency, even in the same laboratory. It seemed apparent that crude extracts were inadequate vaccines. Perhaps there were a few key antigens that needed to be identified, but this begs the question about the mechanisms that a vaccine was intended to elicit. Would the possession of good models of protection assist the process of antigen identification?

\section{Concomitant immunity: the big idea 1969-1979}

The concept of concomitant immunity, introduced by Smithers and Terry (1969), dominated thinking about schistosome immunology and vaccine research for two decades. These researchers reported that when the rhesus macaque (Macaca mulatta) was given an infection, the primary worm burden persisted but the animals were resistant to a secondary cercarial challenge. McCullough and Bradley (1973) tentatively suggested that the concept could be applied to $S$. haematobium infections in humans and the idea became firmly established in the minds of researchers. It posed a very simple and elegant paradigm: discover how the mature primary worms induce protection and you have the basis for a vaccine. Almost simultaneously, the description of the in vitro killing of newly transformed schistosomula by a combination of antibodies, complement and eosinophils (Butterworth et al. 1974), termed antibody-dependent cellular cytotoxicity (ADCC), provided a mechanism to explain how concomitant immunity might operate. Subsequent research showed that several combinations of leucocytes and antibody isotypes were equally effective at parasite killing in vitro (Butterworth 1984).

The mid 1970s was one of those periods of optimism that seem to characterise vaccine development, where the product appears to be within our grasp and just a little more research will bring it to fruition. Thirty years later, with no product near to application, it is pertinent to ask what went wrong. One reason is that work on the rhesus macaque model ceased, before it had been fully characterised, and experimentation shifted to the laboratory mouse. We can speculate that factors such as cost and the need for adequate replication of samples were important criteria driving this change. It was shown both that chronically infected mice could develop concomitant immunity (Dean et al. 1978a), and that the protection could be passively transferred to naïve mice with infection se- rum (Sher et al. 1975). However, the mouse with a chronic infection was always a tricky model, since even a single worm pair could elicit significant morbidity and mortality.

This led researchers to question the immunological basis of the concomitant immunity displayed by chronically infected mice, initially by demonstrating that it required a bisexual infection (Dean et al. 1978b). This implicated eggs as causative agents yet eggs alone, whilst eliciting high antibody titres, could not induce protection (Harrison et al. 1982). The prosaic explanation for concomitant immunity in the mouse was that it represented an artefact of pathology (Wilson et al. 1983). The welldocumented egg-induced pathology causes porta-caval anastomoses to form that allow schistosomula, newly arrived in the portal system, to escape back to the general circulation. Was this also the explanation for concomitant immunity in the rhesus macaque? Recent experiments with this model suggest not (Coulson, unpublished data) and it would be instructive to take another look using modern immunological techniques. However, it seems that the concept of a primary worm burden remaining whilst the host was immune to a challenge was misplaced, with the rhesus macaque's response to infection best being described as a "self cure" phenomenon.

\section{Attenuated parasites induce protective immunity}

Whilst scepticism was growing about the possibility of basing a vaccine on the "immunity" displayed by hosts with a chronic infection, research on the induction of immunity using attenuated cercariae was gathering momentum. Vaccination with attenuated cercariae was first attempted in the early 1960 s, with detailed analysis being undertaken from 1978 onwards (Minard et al. 1978). These studies have demonstrated that high levels of protection can be achieved in mice (>90\%) and primates ( $86 \%$ ) (Wynn et al. 1995, Mountford et al. 1996, Kariuki et al. 2004), and provide the strongest possible evidence that a schistosome vaccine is feasible. The salient features of this attenuated vaccine have been reviewed (Coulson 1997) and, in mice at least, its success appears to require a truncated migration of the attenuated parasites. A small proportion of the larvae enters and persists in the skin-draining lymph nodes where they provoke an immune response greater in intensity and differing in quality from that induced by normal parasites. Other larvae travel only as far as the lungs where they recruit lymphocytes to arm that organ (Coulson \& Wilson 1997).

Both cell-mediated and humoral mechanisms appear to operate, but consecutively rather than simultaneously. Thus, in $1 \times$ vaccinated mice lung schistosomula are the target of focal cellular effector responses mediated by $\mathrm{CD}^{+} \mathrm{T}$ cells of the Th1 subset, with interferon $\gamma$ (INT- $\gamma$ ) and tumor-necrosis factor (TNF) as key cytokines. The bulk of evidence suggests that the effector mechanism relies on blocking intravascular migration rather than cytoxic killing. With multiple exposures of mice to attenuated cercariae, the immune response progressively develops a Th2 profile, with protection passively transferable to naïve recipients with immune serum. However, the level of protection attained with antibodies is never as great as for the cell-mediated mechanism. The immune responses 
of primates to the attenuated vaccine well illustrate this switch, with the cytokine profile changing from Th1 to Th2 with successive exposures to attenuated cercariae (Eberl et al. 2001). In addition, multiple vaccinations are necessary to elicit adequate protection, and in $5 \times$ vaccinated baboons the mechanism is probably antibody-mediated (Kariuki et al. 2004). The big challenge has been, and remains, to identify the antigens that mediate protection in the irradiated vaccine model.

\section{Routes to antigen identification 1980-1995}

The attempts to identify protective antigens, whether based on a particular model, or opportunistically, have tracked new developments in technology, but usually with a lag of several years, as illustrated below:

1975: hybridoma technology developed (Kohler \& Milstein 1975)

1982: first anti-schistosome mAbs (Zodda \& Phillips 1982)

1974: recombinant DNA technology (Berg et al. 1974)

1982: first application of cloning techniques to development of a synthetic vaccine against schistosomiasis (Knopf et al. 1982)

1986: polymerase chain reaction (Mullis et al. 1986)

1991: first application to schistosome antigen cloning (Ali et al. 1991)

A full appraisal of the avenues that have been used to select potentially protective schistosome antigens can be found in Wilson and Coulson (2006) and only the barest outline is given here.

\section{i) Mining crude extracts}

Soluble extracts of schistosomula and adult worms, administered to mice, with BCG as adjuvant (James \& DeBlois 1986), led to the identification of a $97 \mathrm{kDa}$ antigen, paramyosin (Pearce et al. 1988), used in its native form for vaccination experiments.

\section{ii) Monoclonal antibody $(\mathrm{mAb})$ targets}

When first developed, mAb technology seemed to provide a very direct route to the identification of protective antigens. Develop a panel on mAbs, test them for protective potential either directly via ADCC assays or by passive administration to mice, and then identify and clone the antigenic targets. A lot of laboratories followed this route, and as we can testify from personal experience, results were meagre. Nevertheless, three groups reported success, and this led to the development of triose phosphate isomerase (Harn et al. 1992), Sm23 (membrane tetraspanin; Reynolds et al. 1992) and 9B-Ag (Hazdai et al. 1985) as vaccine antigens.

\section{iii) Anti-idiotypes}

The development of anti-idiotype vaccines was a briefly fashionable approach, especially since it offered a way to progress glycan epitopes, not amenable to recombinant DNA technology. Antigens of 38kDa (Grzych et al. 1985) and $68 \mathrm{kDa}$ (Olds \& Kresina 1987) on the surface of schistosomula were selected in this way, but the approach petered out.

\section{iv) Expression library screening}

Molecular biology seemed to offer the best prospect for a vaccine, with unlimited quantities of antigens produced as recombinants in microbial or eucaryotic vectors. The obvious way to identify protective antigens was to screen expression libraries with immune serum. Two antigens emerged from this approach, IrV5, a cloned $62 \mathrm{kDa}$ fragment of myosin heavy chain (Soisson et al. 1992) and a $37 \mathrm{kDa}$ antigen target of immune human serum (Dessein et al. 1988) later identified as glyceraldehyde 3 phosphate dehydrogenase (GAPDH; Goudot-Crozel et al. 1989).

\section{v) Immunogenicity}

The straightforward use of immunogenicity as the criterion for selection as a vaccine candidate was popular, not least because it made cloning easy, although it rather ignored Waksman's postulate that antigens mediating protection will have been selected by immunological pressure for low reactivity. A $28 \mathrm{kDa}$ antigen (Balloul et al. 1985), later identified as glutathione-S-transferase (Sm28GST; Taylor et al. 1988) and fatty acid binding protein (Sm14; Moser et al. 1991) emerged by this route.

The one feature that all the above antigens had in common was an ability to elicit $30-40 \%$ protection, with occasional reports of much higher values, but set against this were papers reporting immunogenicty but not protection data. Since levels of protection elicited by a single antigen were low, several attempts were made to boost vaccine efficacy by combining antigens as protein cocktails, or their epitopes in DNA and synthetic peptide constructs. Unfortunately, no additive effect was recorded, a result that could be interpreted to mean that the various antigens involved (Sm28GST, TPI, Sm23, paramyosin) all conferred protection via the same mechanism.

\section{Is antigen formulation the problem?}

A plausible explanation for the limited success of the recombinant antigen vaccines was incorrect or inadequate formulation to achieve the desired level of protection. It was demonstrated independently that co-administration to mice of the radiation-attenuated cercarial vaccine with the recombinant cytokine IL (interleukin)-12, would increase its efficacy from 60 to $>90 \%$, with some animals showing sterile immunity (Wynn et al. 1995, Mountford et al. 1996), so clearly formulation was an important issue. A great deal of work was published on the utility of various formulations and this is well illustrated by Sm28GST as the test antigen. Professor Capron's laboratory made a formidable effort with:

- synthetic peptides coupled to tetanus toxoid (Auriault et al. 1988) or assembled in an octomer (Wolowczuk et al. 1991);

- cloning into live Salmonella (Khan et al. 1994), BCG (Kremer et al. 1996) and Bordatella pertussis (Mielcarek et al. 1997);

- recombinant GST linked to cholera toxin delivered intranasally (Sun et al. 1999) or in biodegradable particles (Baras et al. 1999); 
- a DNA construct administered with an IL-18 plasmid (Dupre et al. 2001).

Where protection data were published, it appears that no formulation gave a spectacular increase in efficacy.

\section{The independent WHO vaccine trials}

By the early 1990s, progress in expressing recombinant antigens and reports of successful protection in rodents, produced a spirit of optimism in the research community that a vaccine was feasible. This led WHO to provide funds for independent laboratory trials of candidate antigens, and calls were made for researchers to submit their antigens for testing. Two laboratories were selected for this task, The University of York, UK and BMRI, Rockville, MD, US. The antigens proffered were: IrV5, Sm28GST and Sm14 as recombinants, paramyosin as the purified native protein, and TPI and $\mathrm{Sm} 23$ as synthetic peptide constructs. The formulations were defined by the antigen donors as the ones that worked best in their laboratories, which precluded blind testing. The results of the trials were never made public but the WHO reported that "The consolidated results demonstrated that the stated goal of consistent induction of $40 \%$ protection or better was not reached with any of the antigen formulations tested in these trials" (TDR Newsletter, June 1996).

\section{Clinical trials of schistosomiasis vaccines}

Surprisingly, an antigen NOT involved in the WHO trials, Sh28GST, has emerged as the pacemaker for schistosome vaccines and has progressed through Phase I and Phase II clinical trials in humans (Capron et al. 2002). Its development is based on vaccination experiments with Patas monkeys (Erythrocebus patas) where a clear antifecundity effect was reported (Boulanger et al. 1995). If the effect could be replicated in humans, it would hopefully diminish urinary tract pathology and transmission. No adverse side effects were observed in human recipients and high titres of antibodies that neutralised Sh28GST activity were elicited in Phase I and Phase II trials (Capron et al. 2005). Phase III trials are scheduled to begin in Senegal in 2006 (Riveau, pers. commun.).

\section{Why are high levels of protection difficult to achieve?}

Although the attenuated cercarial vaccine can elicit $>80 \%$ protection in rodents and primates, no recombinant vaccine comes anywhere near this efficacy. The levels achieved by the many antigens tested seldom exceed $50 \%$ and average $\sim 30 \%$ (it is also important to remember that journal editors are not interested in publishing negative results). We have already considered antigen formulation - are there other possibilities. For example, do we have the right antigens?

With the exceptions of $\mathrm{Sm} 23$ that could have exposed domains at the tegument surface, most of the antigens tested in the WHO trials, and by other workers, are cytosolic or cytoskeletal components. Thus, paramyosin and IrV5 (myosin) are muscle proteins, although there is controversy as to whether the former is present on the tegument surface (reviewed in Skelly \& Wilson 2006). TPI and GAPDH are glycolytic enzymes and hence cytosolic in location, as are GST (a detoxifying enzyme) and Sm14 (a fatty acid binding protein). In the first proteomic study undertaken on schistosomes, soluble extracts of adult worms (SWAP) were shown to contain several vaccine candidates among the top 50 spots on a 2D gel separation (Curwen et al. 2004). These authors concluded that "it seems counterintuitive that such proteins would form the basis for an effective vaccine". This brings us back to the early trials with crude extracts (Murrell et al. 1975) were they equivalent to a cocktail of recombinants with very similar results? Further, assuming that the internal antigens really do elicit a degree of protection, how might they trigger the immune effector mechanism?

There are several plausible explanations. It is surprising that the occurrence of ADCC in vivo against newly penetrated skin schistosomula has never been convincingly demonstrated. However, after in vitro transformation several candidate antigens (Sm28GST, IrV5, Sm23, 9B-Ag, TPI) have been reported as transiently detected on the parasite surface. Their presence coincides with shedding of the cercarial tegument membranes in vivo (McLaren \& Hockley 1976), and could reflect a transient leakiness of the tegument surface that would explain their vulnerability to ADCC. It should be noted that by $24 \mathrm{~h}$ in vitro (and presumably in vivo) schistosomula are refractory to killing. However, it seems that schistosomes have adapted to this potential ambush, since the vast majority do not enter the dermis and blood vessels until $>48 \mathrm{~h}$ after skin penetration. Does this delay place them beyond the reach of antibodies and leucocytes until their immune evasion mechanisms are in place?

A second explanation, not involving $\mathrm{ADCC}$, has been highlighted by proteomic analysis of the acetabular gland secretions of cercariae (Curwen et al. 2006). The contents of pre- and post-acetabular glands are released by holocrine secretion which means that the entire contents of the gland cell are squeezed out, cytoplasm as well as vesicles. Thus, Cyclophillin, Thioredoxin, GST28, Aldolase, TPI, and Sm14 were detected on 2D gels in descending order of concentration. Three of the WHO vaccine candidates are prominent in this list, but an effector response triggered by secreted antigens would most likely involve blockage of migration by an inflammatory response rather than ADCC (cf. pulmonary effector responses in mice after exposure to the attenuated-cercaria vaccine).

A possible limitation of ADCC was actually put forward by proponents of the mechanism, namely induction of the wrong kind of antibody. In vitro, evidence was obtained that some antibody isotypes (e.g. IgM) can block ADCC (Yi et al. 1986), whilst in vivo in humans, it has been suggested that IgG4 can block IgE-mediated mechanisms (Hagan et al. 1991). There is another limitation of ADCC as a vaccine-induced effector mechanism that has seldom been considered, namely the need for permanent high specific antibody titres because there is no time to mount a secondary response before the penetrating larva loses it susceptibility to attack. The problem is how to maintain such titres over periods of months to years using current vaccine technologies. In our personal opinion antigens eliciting antibodies that mediate ADCC are never 
likely to form more than a component of a multivalent schistosome vaccine.

\section{What are the right antigens?}

In mice given a single exposure to the attenuated cercarial vaccine, the dependence of the effector response on $\mathrm{CD}^{+} \mathrm{T}$ cells means that the relevant antigens must be accessible for processing and presentation by accessory cells. In other words they must be secreted by migrating larvae, or exposed on their epithelial surfaces. Furthermore, the ability of rhesus macaques to eliminate established adult worms appears to rely on slow starvation (PS Coulson, unpublished data) and we hypothesise that gut and tegument function is impaired. Again this implies secreted or membrane antigens as targets. By what possible immune mechanisms could such antigens mediate protective responses?

In the lungs of mice exposed to attenuated cercariae where cell-mediated immunity operates, migration blocked by a tight focus of leucocytes is our favoured hypothesis, and if IFN $\gamma$ is neutralised or TNF signalling is absent, the mechanism fails (Smythies et al. 1992, Street et al. 1999). Furthermore, when mice lacking an IFN $\gamma$ receptor, which cannot mount a cell mediated response, are given 3-5 exposures to attenuated cercariae, their serum will confer passive protection on mice depleted of Complement or lacking a FcR $\gamma$ chain (P. Coulson, unpublished data). This implies that neither complement fixation nor leucocyte attachment to the parasite is involved in the antibody-mediated protection in these defective hosts. Do such protective antibodies operate by enzyme neutralisation, or blocking of receptor/transporter function on tegument and gut epithelia?

\section{How do we identify secreted and surface-exposed proteins?}

The obvious route might appear to be to collect the secretions released by lung schistosomula cultured in vitro, raise antisera against them and screen expression libraries. When we tried this approach, the antigens detected were the same highly immunogenic constituents such as paramyosin, myosin and aldolase found by others (Harrop et al. 1999, 2000). The reason seems to be that even a few damaged or dead larvae in a culture contribute sufficient material to dominate the reactivity of the antibodies elicited, and hence of the clones picked from the expression library. Clearly this is not the way forward.

The sequencing of the $S$. mansoni transcriptome (Verjovski-Almeida et al. 2003) and genome (www. SchistoDB.org) has opened up exciting new possibilities for antigen discovery. These resources allow us to examine gene and protein expression in the target larval and adult worm stages. Such studies are sometimes referred to disparagingly as "fishing expeditions", but at this stage of schistosome vaccine research there is simply no alternative if we are to break new ground. Provided such screens are carried out intelligently, with a clear strategy to select a specific subset of the parasite transcriptome or proteome, then they will deliver much new information. Our analysis of the immune responses involved in protective immunity in authenticated animal models has lead us to concentrate on the secreted and surface-expressed subset of larval and adult worms.

The proteome has been defined as the total protein complement of an organism, tissue, cell or sub-cellular fraction. Proteomics provides a way to link an individual protein to its encoding DNA sequence, and the first step in the process is to separate the complex mixture of proteins under investigation (Ashton et al. 2001). Reproducible 2D electrophoresis was made possible by immobilised $\mathrm{pH}$ gradients and is ideal for soluble proteins such as larval secretions. Protein spots are excised from the gel, trypsinised and subjected to tandem mass spectrometry. The spectra obtained can then be linked to encoding DNA by searching for matches in the transcript and genome databases. Using this approach we have identified $\sim 80 \%$ by volume of the proteins in cercarial acetabular gland secretions (Curwen et al. 2006). Proteases and their inhibitors found included three isoforms of elastase (Salter et al. 2002). SmPepM8 (a novel metalloproteinase), dipeptyl peptidase IV (SmDPP IV) and SmSerp_c (a new serine protease inhibitor). A group of potential immunomodulators included Sm16 (Ramaswamy et al. 1995), three wasp venom homologues (SmSCP a, b and c) and SmKK7 (a protein with homology to a potassium-channel blocker in scorpion venom). All the new proteins found here represent potential vaccine candidates on the basis of their secretion into host skin, and their biological functions in the infection process are also of considerable interest. Collectively they represent the major targets in acetabular gland secretions and so merit a full exploration.

We are applying the same approach to analyse the secretions of skin and lung stage larvae, a tougher proposition as the amount of material available is much less, straining the detection limits of mass spectrometry. We have also characterised the surface of the adult worm tegument (Braschi \& Wilson 2006, Braschi et al. 2006a, b), as a prelude to the same approach with lung schistosomula, the targets of the immunity elicited in mice by attenuated cercariae. The proteins regurgitated by the adult worm in the course of blood feeding have also been investigated (Hall 2005). Potentially, given time, resources and ingenuity it should be possible to define the full range of secreted and surface-exposed proteins of larvae and adults that might serve as vaccine candidates. The greater task is in fact to clone such proteins in a correctly folded and functional state for vaccine trials in mice and, then for the most promising, in baboons that represent a realistic primate model.

The current sensitivity of mass spectrometers makes low abundance proteins difficult to identify. However, possession of the transcriptome and genome data opens up another route to the identification of vaccine candidates. It permits the construction of microarrays for subsets of the transcriptome, with which to explore e.g. stagespecific gene expression, and these data can be combined with in-silico analysis to pinpoint genes encoding secreted or membrane proteins. We have used the approach to compare gene expression in lung schistosomula, relative to six other life cycle stages, enabling us to pinpoint around 30 possible candidates, many with no homology to any known protein (Dillon et al. 2006). In our hands the 
technique appears to be one to two orders of magnitude more sensitive than proteomics but it does suffer one disadvantage. Schistosomes are metazoan parasites with well developed tissues and organs so that the identification of a secreted or membrane antigen in a lung worm tells us nothing about whether it is likely to be accessible to the host immune system in a live worm, or sequestered deep in some internal location.

\section{Conclusions}

As in the period 1980-1990, once again new technologies and information open up the prospect of progress towards the elusive goal of an effective schistosome vaccine. Access to the genome, transcriptome and proteome provide a fantastic opportunity to search for new vaccine candidates. However, we should always bear in mind that schistosomes are not stupid. They have had tens of millions of years to evolve mechanisms that help them survive immune attack from the mammalian host, even an attack orchestrated by our vaccine strategies. Schistosomes are truly a formidable adversary that won't easily be beaten.

\section{REFERENCES}

Ali PO, Jeffs SA, Meadows HM, Hollyer T, Owen CA, Abath FG, Allen R, Hackett F, Smithers SR, Simpson AJ 1991. Structure of Sm25, an antigenic integral membrane glycoprotein of adult Schistosoma mansoni. Mol Biochem Parasitol 45: 215-222.

Ashton PD, Curwen RS, Wilson RA 2001. Linking proteome and genome: how to identify parasite proteins. Trends Parasitol 17: 198-202.

Auriault C, Gras-Masse H, Wolowczuk I, Pierce RJ, Balloul JM, Neyrinck JL, Drobecq H, Tartar A, Capron A 1988. Analysis of T and B cell epitopes of the Schistosoma mansoni $\mathrm{P} 28$ antigen in the rat model by using synthetic peptides. J Immunol 141: 1687-1694.

Balloul JM, Pierce RJ, Grzych JM, Capron A 1985. In vitro synthesis of a 28 kilodalton antigen present on the surface of the schistosomulum of Schistosoma mansoni. Mol Biochem Parasitol 17: 105-114.

Baras B, Benoit MA, Dupre L, Poulain-Godefroy O, Schacht AM, Capron A, Gillard J, Riveau G 1999. Single-dose mucosal immunization with biodegradable microparticles containing a Schistosoma mansoni antigen. Infect Immun 67: 2643-2648.

Berg P, Baltimore D, Boyer HW, Cohen SN, Davis RW, Hogness DS, Nathans D, Roblin R, Watson JD, Weissman S, Zinder ND 1974. Letter: Potential biohazards of recombinant DNA molecules. Science 185: 303.

Boulanger D, Warter A, Trottein F, Mauny F, Bremond P, Audibert F, Couret D, Kadri S, Godin C, Sellin E et al. 1995. Vaccination of patas monkeys experimentally infected with Schistosoma haematobium using a recombinant glutathione S-transferase cloned from $S$. mansoni. Parasite Immunol 17: 361-369.

Braschi S, Wilson RA 2006. Proteins exposed at the adult schistosome surface revealed by biotinylation. Mol Cell Proteomics 5: 347-356.

Braschi S, Borges W, Wilson RA 2006b. Proteomic analysis of the schistosome tegument and its surface membranes. Mem Inst Oswaldo Cruz 101(Suppl.): 167-174.
Braschi S, Curwen RS, Ashton PD, Verjovski-Almeida S, Wilson A 2006a. The tegument surface membranes of the human blood parasite Schistosoma mansoni: a proteomic analysis after differential extraction. Proteomics 6: 14711482.

Butterworth AE 1984. Cell-mediated damage to helminths. $A d v$ Parasitol 23: 143-235.

Butterworth AE, Sturrock RF, Houba V, Rees PH 1974. Antibody-dependent cell-mediated damage to schistosomula in vitro. Nature 252: 503-505.

Capron A, Capron M, Riveau G 2002. Vaccine development against schistosomiasis from concepts to clinical trials. $\mathrm{Br}$ Med Bull 62: 139-148.

Capron A, Riveau G, Capron M, Trottein F 2005. Schistosomes: the road from host-parasite interactions to vaccines in clinical trials. Trends Parasitol 21: 143-149.

Coulson PS 1997. The radiation-attenuated vaccine against schistosomes in animal models: paradigm for a human vaccine? Adv Parasitol 39: 271-336.

Coulson PS, Wilson RA 1997. Recruitment of lymphocytes to the lung through vaccination enhances the immunity of mice exposed to irradiated schistosomes. Infect Immun 65: 4248.

Curwen RS, Ashton PD, Johnston DA, Wilson RA 2004. The Schistosoma mansoni soluble proteome: a comparison across four life-cycle stages. Mol Biochem Parasitol 138: 57-66.

Curwen RS, Ashton PD, Sundaralingam S, Wilson RA 2006. Identification of novel proteases and immunomodulators in the secretions of schistosome cercariae that facilitate host entry. Mol Cell Proteomics 5: 835-844.

Dean DA, Minard P, Murrell KD, Vannier WE 1978a. Resistance of mice to secondary infection with Schistosoma mansoni. II. Evidence for a correlation between egg deposition and work elimination. Am J Trop Med Hyg 27: 957965.

Dean DA, Minard P, Stirewalt MA, Vannier WE, Murrell KD 1978b. Resistance of mice to secondary infection with Schistosoma mansoni. I. Comparison of bisexual and unisexual initial infections. Am J Trop Med Hyg 27: 951-956.

Dessein AJ, Begley M, Demeure C, Caillol D, Fueri J, dos Reis MG, Andrade ZA, Prata A, Bina JC 1988. Human resistance to Schistosoma mansoni is associated with IgG reactivity to a $37-\mathrm{kDa}$ larval surface antigen. J Immunol 140: 2727-2736.

Dillon GP, Feltwell T, Skelton JP, Ashton PD, Coulson PS, Quail MA, Nikolaidou-Katsaridou N, Wilson RA, Ivens AC 2006. Microarray analysis identifies genes preferentially expressed in the lung schistosomulum of Schistosoma mansoni. Int J Parasitol 36: 1-8.

Doenhoff MJ, Kusel JR, Coles GC, Cioli D 2002. Resistance of Schistosoma mansoni to praziquantel: is there a problem? Trans R Soc Trop Med Hyg 96: 465-469.

Doenhoff MJ, Sabah AA, Fletcher C, Webbe G, Bain J 1987. Evidence for an immune-dependent action of praziquantel on Schistosoma mansoni in mice. Trans $R$ Soc Trop Med Hyg 81: 947-951.

Dupre L, Kremer L, Wolowczuk I, Riveau G, Capron A, Locht 
C 2001. Immunostimulatory effect of IL-18-encoding plasmid in DNA vaccination against murine Schistosoma mansoni infection. Vaccine 19: 1373-1380.

Eberl M, Langermans JA, Frost PA, Vervenne RA, van Dam GJ, Deelder AM, Thomas AW, Coulson PS, Wilson RA 2001. Cellular and humoral immune responses and protection against schistosomes induced by a radiation-attenuated vaccine in chimpanzees. Infect Immun 69: 5352-5362.

Goudot-Crozel V, Caillol D, Djabali M, Dessein AJ 1989. The major parasite surface antigen associated with human resistance to schistosomiasis is a $37-\mathrm{kD}$ glyceraldehyde-3P-dehydrogenase. $J$ Exp Med 170: 2065-2080.

Grzych JM, Capron M, Lambert PH, Dissous C, Torres S, Capron A 1985. An anti-idiotype vaccine against experimental schistosomiasis. Nature 316: 74-76.

Hagan P, Blumenthal UJ, Dunn D, Simpson AJ, Wilkins HA 1991. Human IgE, IgG4 and resistance to reinfection with Schistosoma haematobium. Nature 349: 243-245.

Hall SL 2005. The Use of Proteomic Techniques to Identify Antibody Ttargets in Schistosomiasis, $\mathrm{PhD}$ thesis, University of York, York.

Harn DA, Gu W, Oligino LD, Mitsuyama M, Gebremichael A, Richter D 1992. A protective monoclonal antibody specifically recognizes and alters the catalytic activity of schistosome triose-phosphate isomerase. J Immunol 148: 562-567.

Harris AR, Russell RJ, Charters AD 1984. A review of schistosomiasis in immigrants in Western Australia, demonstrating the unusual longevity of Schistosoma mansoni. Trans $R$ Soc Trop Med Hyg 78: 385-388.

Harrison RA, Bickle Q, Doenhoff MJ 1982. Factors affecting the acquisition of resistance against Schistosoma mansoni in the mouse. Evidence that the mechanisms which mediate resistance during early patent infections may lack immunological specificity. Parasitology 84: 93-110.

Harrop R, Coulson PS, Wilson RA 1999. Characterization, cloning and immunogenicity of antigens released by lung-stage larvae of Schistosoma mansoni. Parasitology 118 (Pt 6): 583-594.

Harrop R, Jennings N, Mountford AP, Coulson PS, Wilson RA 2000. Characterization, cloning and immunogenicity of antigens released by transforming cercariae of Schistosoma mansoni. Parasitology 121 (Pt 4): 385-394.

Hayunga EG 1985. Attempted immunization of mice against $S$. mansoni by inoculation with purified glycoprotein antigens from adult worms. Proc Helminth Soc 52: 184-195.

Hazdai RT, Levi-Schaffer F, Brenner V, Horowitz S, Eshhar Z, Arnon R 1985. Protective monoclonal antibody against Schistosoma mansoni: antigen isolation, characterization, and suitability for active immunization. J Immunol 135: 27722779 .

James SL, DeBlois LA 1986. Induction of protective immunity against Schistosoma mansoni by a nonliving vaccine. II. Response of mouse strains with selective immune defects. J Immunol 136: 3864-3871.

Kariuki TM, Farah IO, Yole DS, Mwenda JM, Van Dam GJ, Deelder AM, Wilson RA, Coulson PS 2004. Parameters of the attenuated schistosome vaccine evaluated in the olive baboon. Infect Immun 72: 5526-5529.

Khan CM, Villarreal-Ramos B, Pierce RJ, Riveau G, Demarco de Hormaeche R, McNeill H, Ali T, Fairweather N, Chatfield S, Capron A et al. 1994. Construction, expression, and immunogenicity of the Schistosoma mansoni P28 glutathione S-transferase as a genetic fusion to tetanus toxin fragment $C$ in a live Aro attenuated vaccine strain of Salmonella. Proc Natl Acad Sci US A 91: 11261-11265.

King CH, Dickman K, Tisch DJ 2005. Reassessment of the cost of chronic helmintic infection: a meta-analysis of disability-related outcomes in endemic schistosomiasis. Lancet 365: 1561-1569.

Knopf PM, Srivastava BS, Barker Jr. RH 1982. Application of cloning techniques to development of a synthetic vaccine against schistosomiasis. Vet Parasitol 10: 255-259.

Kohler G, Milstein C 1975. Continuous cultures of fused cells secreting antibody of predefined specificity. Nature 256: 495-497.

Kremer L, Riveau G, Baulard A, Capron A, Locht C 1996. Neutralizing antibody responses elicited in mice immunized with recombinant bacillus Calmette-Guerin producing the Schistosoma mansoni glutathione S-transferase. J Immunol 156: 4309-4317.

McCullough FS, Bradley DJ 1973. Egg output stability and the epidemiology of Schistosoma haematobium. I. Variation and stability in Schistosoma haematobium egg counts. Trans $R$ Soc Trop Med Hyg 67: 475-490.

McLaren DJ, Hockley DJ 1976. Schistosoma mansoni: the occurrence of microvilli on the surface of the tegument during transformation from cercaria to schistosomulum. Parasitology 73: 169-187.

Mielcarek N, Cornette J, Schacht AM, Pierce RJ, Locht C, Capron A, Riveau G 1997. Intranasal priming with recombinant Bordetella pertussis for the induction of a systemic immune response against a heterologous antigen. Infect Immun 65: 544-550.

Minard P, Dean DA, Jacobson RH, Vannier WE, Murrell KD 1978. Immunization of mice with cobalt-60 irradiated Schistosoma mansoni cercariae. Am J Trop Med Hyg 27: 76-86.

Moser D, Tendler M, Griffiths G, Klinkert MQ 1991. A 14$\mathrm{kDa}$ Schistosoma mansoni polypeptide is homologous to a gene family of fatty acid binding proteins. $\mathrm{J} \mathrm{Biol} \mathrm{Chem} 266$ : $8447-8454$

Mountford AP, Anderson S, Wilson RA 1996. Induction of Th1 cell-mediated protective immunity to Schistosoma mansoni by co-administration of larval antigens and IL-12 as an adjuvant. J Immunol 156: 4739-4745.

Mullis K, Faloona F, Scharf S, Saiki R, Horn G, Erlich H 1986. Specific enzymatic amplification of DNA in vitro: the polymerase chain reaction. Cold Spring Harb Symp Quant Biol 51 (Pt 1): 263-273.

Murrell KD, Dean DA, Stafford EE 1975. Resistance to infection with Schistosoma mansoni after immunization with worm extracts or live cercariae: role of cytotoxic antibody in mice and guinea pigs. Am J Trop Med Hyg 24: 955-962.

Olds GR, Kresina TF 1987. Protective anti-idiotype vaccine against Schistosoma mansoni infection. Trans Assoc Am Physicians 100: 215-221.

Pearce EJ, James SL, Hieny S, Lanar DE, Sher A 1988. Induction of protective immunity against Schistosoma mansoni by vaccination with schistosome paramyosin (Sm97), a 
nonsurface parasite antigen. Proc Natl Acad Sci USA 85: $5678-5682$.

Ramaswamy K, Salafsky B, Potluri S, He YX, Li JW, Shibuya T 1995. Secretion of an anti-inflammatory, immunomodulatory factor by Schistosomulae of Schistosoma mansoni. J Inflamm 46: 13-22.

Reynolds SR, Shoemaker CB, Harn DA 1992. T and B cell epitope mapping of SM23, an integral membrane protein of Schistosoma mansoni. J Immunol 149: 3995-4001.

Sadun EH, Lin SS 1959. Studies on the host parasite relationships to Schistosoma japonicum. IV. Resistance acquired by infection, by vaccination and by the injection of immune serum, in monkeys, rabbits and mice. $J$ Parasitol 45: 543548.

Salter JP, Choe Y, Albrecht H, Franklin C, Lim KC, Craik CS, McKerrow JH 2002. Cercarial elastase is encoded by a functionally conserved gene family across multiple species of schistosomes. J Biol Chem 277: 24618-24624.

Sher A, Smithers SR, Mackenzie P 1975. Passive transfer of acquired resistance to Schistosoma mansoni in laboratory mice. Parasitology 70 Part 3: 347-357.

Silveira AM, Gazzinelli G, Alves-Oliveira LF, Bethony J, Gazzinelli A, Carvalho-Queiroz C, Alvarez MC, Lima-Silva FC, Prata A, LoVerde PT, Correa-Oliveira R 2004. Human schistosomiasis mansoni: intensity of infection differentially affects the production of interleukin-10, interferongamma and interleukin-13 by soluble egg antigen or adult worm antigen stimulated cultures. Trans $R$ Soc Trop Med Hyg 98: 514-519.

Skelly, PM, Wilson RA 2006. Making sense of the schistosome surface. Adv Parasitol in press.

Smithers SR, Terry RJ 1969. Immunity in schistosomiasis. Ann NY Acad Sci 160: 826-840.

Smythies LE, Coulson PS, Wilson RA 1992. Monoclonal antibody to IFN-gamma modifies pulmonary inflammatory responses and abrogates immunity to Schistosoma mansoni in mice vaccinated with attenuated cercariae. J Immunol 149: 3654-3658.

Soisson LM, Masterson CP, Tom TD, McNally MT, Lowell GH, Strand M 1992. Induction of protective immunity in mice using a 62-kDa recombinant fragment of a Schistosoma mansoni surface antigen. J Immunol 149: 3612-3620.

Street M, Coulson PS, Sadler C, Warnock LJ, McLaughlin D, Bluethmann H, Wilson RA 1999. TNF is essential for the cell-mediated protective immunity induced by the radiation-attenuated schistosome vaccine. J Immunol 163: 44894494.

Sun JB, Mielcarek N, Lakew M, Grzych JM, Capron A, Holmgren J, Czerkinsky C 1999. Intranasal administration of a Schistosoma mansoni glutathione S-transferase-chol- era toxoid conjugate vaccine evokes antiparasitic and antipathological immunity in mice. J Immunol 163: 10451052.

Taylor JB, Vidal A, Torpier G, Meyer DJ, Roitsch C, Balloul JM, Southan C, Sondermeyer P, Pemble S, Lecocq JP et al. 1988. The glutathione transferase activity and tissue distribution of a cloned Mr28K protective antigen of Schistosoma mansoni. Embo J 7: 465-472.

van der Werf MJ, de Vlas SJ, Brooker S, Looman CW, Nagelkerke NJ, Habbema JD, Engels D 2003. Quantification of clinical morbidity associated with schistosome infection in subSaharan Africa. Acta Trop 86: 125-139.

Verjovski-Almeida S, DeMarco R, Martins EA, Guimaraes PE, Ojopi EP, Paquola AC, Piazza JP, Nishiyama MY, Jr., Kitajima JP, Adamson RE, Ashton PD, Bonaldo MF, Coulson PS, Dillon GP, Farias LP, Gregorio SP, Ho PL, Leite RA, Malaquias LC, Marques RC, Miyasato PA, Nascimento AL, Ohlweiler FP, Reis EM, Ribeiro MA, Sa RG, Stukart GC, Soares MB, Gargioni C, Kawano T, Rodrigues V, Madeira AM, Wilson RA, Menck CF, Setubal JC, Leite LC, Dias-Neto E 2003. Transcriptome analysis of the acoelomate human parasite Schistosoma mansoni. Nat Genet 35: 148-157.

Wilson RA, Coulson PS 2006. The development of a schistosome vaccine. In AG Maule, NJ Marks (eds), Parasitic Flatworms: Molecular Biology, Biochemistry, Immunology and Physiology, CAB International, Wallingford, UK.

Wilson RA, Coulson PS, McHugh SM 1983. A significant part of the 'concomitant immunity' of mice to Schistosoma mansoni is the consequence of a leaky hepatic portal system, not immune killing. Parasite Immunol 5: 595-601.

Wolowczuk I, Auriault C, Bossus M, Boulanger D, Gras-Masse H, Mazingue C, Pierce RJ, Grezel D, Reid GD, Tartar A et al. 1991. Antigenicity and immunogenicity of a multiple peptidic construction of the Schistosoma mansoni $\mathrm{Sm}-28$ GST antigen in rat, mouse, and monkey. 1. Partial protection of Fischer rat after active immunization. J Immunol 146: 1987-1995.

Wynn TA, Jankovic D, Hieny S, Cheever AW, Sher A 1995. IL12 enhances vaccine-induced immunity to Schistosoma mansoni in mice and decreases T helper 2 cytokine expression, IgE production, and tissue eosinophilia. J Immunol 154: 4701-4709.

Yi XY, Omer-Ali P, Kelly C, Simpson AJ, Smithers SR 1986. IgM antibodies recognizing carbohydrate epitopes shared between schistosomula and miracidia of Schistosoma mansoni that block in vitro killing. J Immunol 137: 39463954.

Zodda DM, Phillips SM 1982. Monoclonal antibody-mediated protection against Schistosoma mansoni infection in mice. J Immunol 129: 2326-2328. 